\title{
AESCRITURA DE UM EFÊMERO: ASPECTOS DA RELEITURA DA OBRA BAUDELAIRIANA EM UNE HISTOIRE DE BLEU, DE JEAN-MICHEL MAULPOIX
}

\section{SCRIPTURE AN EPHEMERAL: ASPECTSOF READING IN THE WORKBAUDELAIREAN UNE HISTOIRE DE BLEU, JEAN-MICHEL MAULPOIX}

Erica MILANEZE ${ }^{1}$

\begin{abstract}
RESUMO: No cenário da poesia francesa contemporânea, o lirismo crítico expressa um prolongamento das tendências de recuperação da escrita lírica iniciada nos anos 80 do século XX. Neste contexto, os ensaios e os textos poéticos de Jean-Michel Maulpoix são representativos desta vertente poética, especialmente Une histoire de bleu, onde o poeta exterioriza sua interioridade e efetua uma reflexão sobre seus sentimentos e suas dúvidas, ao mesmo tempo em que questiona a realidade exterior e a linguagem poética. Além
\end{abstract}

\footnotetext{
1 Pós-doutoranda em História e crítica literária e professora colaboradora do Departamento de Teoria Literária, Instituto de Estudos da Linguagem, Universidade Estadual de Campinas, UNICAMP, CEP 13083-859, Campinas, SP, Brasil. Pesquisadora da Fundação de Amparo à Pesquisa do Estado de São Paulo (FAPESP). email: erica.milaneze@gmail.com.
} 
disso, Une histoire de bleu revela uma releitura da obra de Charles Baudelaire em consonância com as formulações críticas de Maulpoix, que se confessa herdeiro do poeta da modernidade. Pretendemos analisar alguns aspectos da releitura efetuada por Jean-Michel Maulpoix em Une histoire de bleu da obra baudelairiana para compreender seu papel nos mecanismo de construção do lirismo crítico no interior do texto e a influência do poeta da modernidade no projeto estético do autor contemporâneo.

PALAVRAS-CHAVE: poesia francesa; poesia contemporânea; lirismo crítico; Jean-Michel Maulpoix; literatura contemporânea

\begin{abstract}
In scenario of contemporary French poetry,the critical lyricism expresses a prolongation of the trends of recovery of lyric writing initiated in the 80s of XX century. In this context, the trials and the poetic texts of Jean-Michel Maulpoix are representative of this poetic trend, especially Une histoire de bleu, where the poet externalizes his inner self and makes a reflection on their feelings and doubts, while questioning the external reality and poetic language. Furthermore, Une histoire de bleu reveals a reading of the work of Charles Baudelaire in agreement with the critical formulations Maulpoix, which the poet confesses heir of modernity. We intend to analyze some aspects of rereading carried out by Jean-Michel Maulpoix in Une histoire de bleu of Baudelaire's work to understand their role in the construction the critical lyricism in the interior of text and the influence of the poet of modernity in the contemporary design esthetic mechanism author.
\end{abstract}

KEYWORDS: French poetry; contemporary poetry; critical lyricism; Jean-Michel Maulpoix; contemporary literature

No diversificado e rico cenário da poesia francesa dos últimos trinta anos, os ensaios críticos e as obras poéticas de Jean-Michel Maulpoix (1952) são representativos do lirismo crítico, vertente estética que expressa um prolongamento do movimento de 
renovação lírica que, por volta dos anos 80 do século $\mathrm{XX}$, inicia uma reação à produção das várias vertentes que perfazem as neovanguardas dos anos de 1960 e 1970 . Predominantemente voltadas para a experimentação e a abstração, estas neo-vanguardas legam o lirismo para segundo plano a favor da literalidade, sendo a póspoesia no contexto atual uma de suas herdeiras mais proeminentes na medida em que se contrapõe às vertentes neo-líricas, propondo ainda uma "saída" de todos os modelos consagrados pela tradição da poesia.

Neste cenário literário, os trabalhos de Maulpoix revelam sua importância porque trazem uma abordagem teórica mais ampla e aprofundada do complexo conceito de lirismo por meio de sua investigação desde sua origem no Romantismo francês até sua reatualização ao contexto contemporâneo, onde desenvolve o conceito de lirismo crítico. Para Maulpoix (2009, p.09), o lirismo não se reduz nem a ideia simplista de um fluxo verbal exacerbado e de uma efusão dos sentimentos, nem a uma incompatibilidade com a literalidade - opinião compartilhada por críticos como Pinson (1995) e Collot (2006); isto porque, considera o lirismo como um estado poético em que o sujeito sofre ou se beneficia de um "acesso" de linguagem, correspondendo à maneira como o sujeito se coloca no texto poético, ou seja, ao movimento da linguagem dentro do corpo e na voz do sujeito que se transforma em escrita (MAULPOIX, 2000, p.23). No ensaio La poésie comme l'amour (1998), Maulpoix descreve outras formas, além do lirismo crítico, por meio das quais o lirismo pode se manifestar na literatura contemporânea, inclusive no interior das tendências experimentais e literais: lirismo do movimento; do embaralhamento; do prosaico; da precariedade; da alteridade; da voz; da desilusão. Na verdade, o lirismo crítico expressa um outro encaminhamento possível para a produção contemporânea em relação às propostas da pós-poesia, pois defende a persistência da 'poésie malgré tout'. De fato, o lirismo crítico procura preservar a voz e as emoções do sujeito apesar dos riscos de cair no pathos e no sentimentalismo; assim, crítico é o lirismo 
que escava mais que eleva, interroga mais que celebra, "critique, cette écriture qui se retourne anxieusement sur elle-même au lieu de chanter dans l'insouciance. Mais lyrique cependant, puisque les questions qu'elle pose restent indissociables de l'émotion d'un sujet et de la circonstance vécue." (MAULPOIX, 2009, p.21). Quando assume uma postura crítica, o lirismo atua como um articulador entre as emoções do sujeito, a realidade exterior e a linguagem, ao mesmo tempo em que examina, analisa e investiga em uma atitude metapoética sua escrita e o impulso lírico.

Ao longo do processo de reavaliação do lirismo, Maulpoix se detém na investigação da modernidade poética, encontrando na obra de Charles Baudelaire a gênese de um lirismo que se torna crítico, pois se afasta do sentimentalismo, da efusão, do pathos, da inspiração - exacerbados por uma certa vertente romântica - e, ao trazer a consciência crítica para o ato criador, acaba por transformar o lirismo em um lugar crítico (MAULPOIX, 2000, p. 89). É interessante citar as considerações de André Gide, em sua Anthologie de la poésie française (1949), sobre a contribuição de Baudelaire para a renovação das concepções poéticas promovidas pela modernidade, utilizadas inclusive por Maulpoix para reforçar seu argumento, porque advém de um crítico e romancista que presencia de modo mais imediato os efeitos que as mudanças estéticas do final do século XIX determinam no início do século XX:

L'on ne s'aperçut pas aussitôt de l'extraordinaire nouveauté qu'apporta Baudelaire dans le champ de la poésie; on ne consentit à voir dans Les Fleurs du mal que la nouveauté des sujets traités (ce qui n'avait que peut d'importance); mais c'était une révolution sans précédant que de ne plus s'abandonne aux flux lyrique, de résister à la facilité de 'inspiration', au laisser-aller rhétorique, à l'entraînement des mots, des images et des conventions surannées; que de traiter la Muse en rétive, qu'il faut soumettre au lieu de s'en remettre à elle, esprit et sens critique liés, bref: que d'inviter l'art à maîtriser la poésie (GIDE, 1949 apud MAULPOIX, 2000, p. 88). 
Dentre as obras poéticas de Jean-Michel Maulpoix, Une histoire de bleu, publicada em 1992, corresponde a seu primeiro texto poético no âmbito do lirismo crítico. Nela os versos cedem lugar a uma prosa que se coloca nas fronteiras com a poesia, ao mesmo tempo em que questiona a escrita poética e o ímpeto lírico. Com efeito, o poeta exterioriza sua interioridade e efetua uma reflexão acerca de seus sentimentos, dúvidas e crenças, enquanto interroga a realidade exterior e a linguagem poética por meio do motivo da cor azul, que adquire nas diversas pequenas prosas que compõem a obra um sentido polissêmico - é a cor do céu, do mar, do amor, da morte, da melancolia, do olhar, do ideal, da religiosidade, etc. -, construindo uma rede complexa de reflexões e questionamentos, que lhe permite dar conta de suas experiências e emoções depreendidas pelo contato com o mundo exterior pelo ato da escrita. Matéria fluida, visível e a um só tempo invisível, que se expande pelo espaço exterior, impregnando a interioridade dos seres e das coisas, o azul ou "bleu" se transforma nas emoções que determinam o estado poético, mistura-se ao corpo, estimula a voz a exteriorizar o canto e, ainda, desencadeia uma disposição interior no sujeito que lhe permite perceber suas mais tênues manifestações na realidade exterior. $\mathrm{O}$ azul envolve, então, tanto a paisagem quanto o ser humano, reunindo a vida e a escrita na medida em que é a manifestação da poesia na matéria e nos sentimentos:

Ce n'est pas, à vrai dire, une couleur. Plutôt une tonalité, un climat, une résonance spéciale de l'air. Un empilement de clarté, une teinte qui naît du vide ajouté au vide, aussi changeante et transparente dans la tête de l'homme que dans les cieux.

L'air que nous respirons, l'apparence de vide sur laquelle remuent nos figures, l'espace que nous traversons n'est rien d'autre que ce bleu terrestre, invisible tant il est proche et fait corps avec nous, habillant nos gestes et nos voix. Présent jusque dans la chambre, tous volets tires et toutes lampes éteintes, insensible vêtement de notre vie. (MAULPOIX, 2005b, p. 67). 
Desta forma, o azul pode ser considerado, conforme a definição de Collot (1997), uma matéria-emoção que corresponde ao próprio lirismo tal qual o define Maulpoix.

Analisando alguns aspectos da releitura de Jean-Michel Maulpoix da obra baudelariana, depreendemos que Une histoire de bleu se vincula à escrita de um efêmero em que a linguagem lírica e crítica se apóia no aspecto transitório das vivências do poeta que lança seu olhar para o universo exterior com o intuito de construir uma escrita que dê conta de sua interação com a realidade contemporânea. Situado no contexto do final do século XX, o poeta exterioriza a melancolia causada pela consciência da impossibilidade definitiva de satisfazer seu desejo de atingir o Ideal - ou "L'Azur" como o denomina Mallarmé em seu famoso poema - e de sua condição de criatura finita irremediavelmente presa nos limites da realidade terrena: "L'azur est lettre morte, l'horizon est indéchiffrable. On se demande comment rester debout dans ce paquet de chair. La terre n'est pas si difficile: elle veut bien de nos os. Mais le ciel bleu dédaigne notre paleur" (MAULPOIX, 2000, p. 63), como ressalta em Une histoire de bleu. Maulpoix (2006, s.p.) se confessa herdeiro da modernidade a partir de "L'Albatroz" baudelairiano, claudicando entre sua época e a tentação de uma retirada intemporal na natureza. Tal postura diante da transcendência e da realidade contingente percorre as obras do autor e revela que a reinterpretação da modernidade conforme a define Baudelaire, em $O$ Pintor da vida moderna (1863), fornece o suporte para a constituição de um texto lírico e crítico, em que o lirismo se coloca em uma posição intermediária de maneira a articular a subjetividade, o mundo exterior e a linguagem em uma relação estreita e complexa. Assim, o poeta permanece no espaço entre o céu e a terra, entre o "ici" e o "là-bas", espaço "entre-deux" ou intermediário que compõe o limite de seu horizonte - espacialidade preenchida pelo "bleu" em Une histoire de bleu - e, por conseguinte, a paisagem que visualiza e o envolve, onde transcorrem suas percepções e sensações. A paisagem romântica se caracteriza por um horizonte ilimitado que 
se abre para o infinito, o qual o poeta anseia por ultrapassar para entrever a divindade que, entretanto, não se deixa revelar. Contudo, para os românticos a metáfora do horizonte exprime de modo radical e dramático o recuo de Deus em uma profundeza inacessível (COLLOT, 1988, p. 53). Com a modernidade, o horizonte adquire uma conotação negativa, uma vez que oferece ao olhar a imagem de um infinito cósmico esvaziado da presença divina e de dimensões desproporcionais diante da finitude humana. 0 horizonte se apresenta, então, como uma abertura vazia que se fecha sobre a paisagem, juntamente com a parcela do céu e da terra que lhe é contígua (COLLOT, 1988, p. 73-6). Tal a imagem do horizonte que permanece até os dias atuais, da qual Maulpoix se nutre em Une histoire de bleu.

O poeta francês Jean-Claude Pinson, no ensaio Habiter en poète (1995) lembra que a reabilitação da realidade contingente é um fenômeno que se desenvolve de modo mais específico na literatura moderna, principalmente na poesia, que a torna um referente privilegiado. Lembrando as afirmações de Northrop Frye em Anatomia da crítica (1957), Pinson (1995, p.97) comenta que a produção moderna "voit son centre de gravité se déplacer peu à peu du haut vers le bas, de l'idéal vers le réel, du nobre vers le grotesque, du merveilleux vers le trivial.". Quando se acompanha, ainda conforme Pinson (1995, p.97), esta evolução ao longo do tempo, constata-se que pertence também "à l'échelle plus resserrée de la poésie contemporaine", como aponta, inclusive, o poeta Philippe Jaccottet (1992, p. 268).

Ao efetuar a releitura da definição baudelairiana, "a modernidade é o transitório, o fugaz, o contingente, a metade da arte cuja metade restante é eterna e imutável" (BAUDELAIRE, 2010, p.35). Maulpoix se detém na relação que o aspecto transitório estabelece com o ser humano inserido em um determinado intervalo temporal, ou seja, o transitório é a condição do homem que "naît, qui souffre et qui meurt. Avec ses affections, ses vices, tribut payé au temps et à autrui. Les avatars singuliers d'une disparition, rien de plus." 
(MAULPOIX, 1998, p. 69). Interessa para Maulpoix compreender a transitoriedade como uma condição individual e, portanto, variável para cada ser humano dentro de um único ou em diferentes contextos sociais, históricos e culturais. De acordo com este ponto de vista, perfaz o período de duração da vida de cada homem com suas experiências, percepções e sensações desenvolvidas por meio do contato com os outros seres humanos e com a realidade contingente desde o seu nascimento até a sua morte. É nesta direção que incide a reflexão de Maulpoix acerca do que venha a ser o contemporâneo:

Je suis, comme quiconque, [...] le contemporain des gens que je croise et de ceux avec qui je partage mon temps, de ceux à qui je donne de mon temps, de ceux avec qui je prends ou je perds mon temps. [...] Je suis le contemporain de mes sensations, mes désirs, mes chimères, mes oublis, mes pensées. Je suis le contemporain de tout ce qui insiste en moi. Je suis le contemporain du corps de ma mère dont après un demi siècle d'efforts j'ai toujours bien du mal à (me) sortir. Je suis le contemporain de ceux que j'aime, parce que ceux que j'aime m'offrent du temps et des raisons de vivre. Je suis le contemporain de mon transitoire. D'un enfant qui naît et d'un homme qui meurt (MAULPOIX, 2005a, p. 52-4).

Neste intercâmbio entre a subjetividade e a alteridade, Maulpoix se considera, junto com seus semelhantes, contemporâneo de um contexto mais amplo que abrange toda sua época, esta também extremamente contingente, da qual nenhum ser humano pode escapar: "Je suis donc le contemporain de George Bush et de Ben Laden, de Star Academy et d'Yves Bonnefoy, de BHL et du DVD, du téléphone portable, d'Internet et du Mac Do, etc." (MAULPOIX, 2005a, p. 52). Ora, ao tomar o transitório do ponto de vista do sujeito, o autor aproxima o conceito de modernidade formulado por Baudelaire da maneira como entende o contemporâneo, pois a vida humana se concretiza em uma temporalidade transitória em qualquer momento histórico ou social. Desta forma, o poeta 
como qualquer outro ser humano com quem compartilha sua contemporaneidade participa do caráter efêmero da vida que se insere, por sua vez, em um presente também contingente. Em Une histoire de bleu, o poeta denota um sentimento de tristeza frente à consciência da transitoriedade da vida e da realidade exterior, relacionando-a também com a precariedade das palavras em transmitir as vivências em sua amplitude e inteireza diante da finitude: "Nous sommes ici pour peu de temps: quelques mots, quelques phrases, si peu sous les étoiles, rien que cela, parmi tout le reste." (MAULPOIX, 2005b, p. 39).

Neste sentido, o transitório observado por Baudelaire como uma das faces da modernidade será explorado por Maulpoix em diversas acepções ${ }_{\boldsymbol{L}}$ a fim de construir os laços entre a subjetividade e a alteridade, articulação que caracteriza um dos aspectos do lirismo crítico, que corresponde também a "une écriture lyrique tendue par et vers l'altérité (épreuve de l'altérité en soi et au-dehors de soi) et qui met en examen la poussée lyrique» (MAULPOIX, 2001, s.p.). Esta escrita lírica apresenta, a meu ver, um dinamismo que é responsável pela transição da interioridade à realidade exterior, que compreende tanto as coisas quanto os outros seres humanos, sendo um instrumento articulatório que estabelece uma continua circulação entre o mundo interior e o exterior.

Na esteira baudelairiana, o autor contemporâneo "prend du transitoire son parti" para elaborar a partir dele uma escrita poética, em que o lirismo se torna o esforço articulatório que faz de uma vida uma voz e que busca uma possível coincidência entre o movimento da pluma e o passo do destino (MAULPOIX, 2000, p. 89). Converter as experiências vivenciadas ao longo da vida em uma voz e, consequentemente, em uma escrita que consiga apreender as sensações e as percepções na efemeridade de seu presente e da presença, tal o anseio que Maulpoix tenta materializar nas pequenas prosas de Une histoire de bleu. Unindo a vida à escrita, o poeta contemporâneo busca uma forma possível de se adaptar à realidade na qual se insere, ou seja, de "habitar" poeticamente 
a vida e o mundo, postura que caracteriza toda uma vertente do lirismo contemporâneo que deseja dizer a vida e o mundo por meio da subjetividade, em oposição às tendências experimentais neo-vanguardistas e à pós-poesia que desenvolvem uma poética do evento ao se colocarem à escuta do que a vida diz a partir do trabalho com a linguagem (GAME, 2001, s.d.).

Para tanto, Maulpoix recupera o transitório no sentido do ato de transitar, do deslocamento de um lugar para outro no espaço, o que implica um sujeito em um constante movimento em sintonia com as transformações ininterruptas da realidade que o cerca, onde as mudanças estão cada vez mais aceleradas e intensas desde a modernidade até a sociedade midiática e tecnológica contemporânea. Se, como lembra Maulpoix (1998, p. 72), o caminhante solitário que foi Rousseau andava pelos bosques em busca de elevação por meio da comunhão com a natureza no final do século XVIII, o "rôdeur" baudelairiano perambula e não mais caminha pelos espaços naturais na segunda metade do século XIX, mas pela grande cidade em intenso processo de transformação, fragmentado entre o spleen e o ideal, tendo-se, portanto, dois diferentes tipos de deslocamento. 0 trajeto lírico do solitário»rôdeur», segundo a leitura de Maulpoix (2005a, p. 176), é uma atitude dolorosa em busca de extrair a beleza do mal, pois o poeta espera que, ao agravar os aspectos negativos da realidade urbana e dos efeitos destes na vida humana, possa se elevar apesar de todos os obstáculos. Se existe algum ímpeto vertical para o ideal na obra baudelairiana, este se manifesta apenas na solidão do quarto “'à une heure du matin', lorsque l'artiste retranché appelle à lui la grâce de quelques beaux vers. Le reste du temps, la verticalité est barrée, étouffée par un lourd couvercle" (MAULPOIX, 2000, p. 90). Já o poeta contemporâneo, tal qual o concebe Maulpoix, tende a se situar tanto na solidão de seu quarto quanto na profusão das ruas da cidade, movimentando-se ou transitando de um espaço para outro: 
Mobile, plutôt que penché sur le vierge papier [...] C'est [...] une abeille qui va et vient sans cesse de la route à la chambre et qui rapporte son butin dans 'la ruche de l'invisible'. Et c'est parce qu'il est lui-même une espèce d'oeil double, partagé, divisé de l'intérieur, qu'il ne peut trouver d'apaisement que dans le mouvement. (MAULPOIX, 2009, p. 35, grifo nosso).

O poeta lírico-crítico se situa em uma posição intermediária, em um "entre-deux", como o próprio lirismo crítico, mantendo-se em um frágil equilíbrio devido à intensa movimentação entre a interioridade e a realidade exterior, em um deslocamento constante "d'aller et de venir" entre o quarto e a rua, da escrita para a vida e vice-versa: "[...] sans cesser, il [le lyrisme/le poète] continue d'aller et de venir entre la chambre et la rue, la page et les vivants" (MAULPOIX, 2009, p.32).

Com efeito, em Une histoire de bleu, o poeta realiza um itinerário de seu quarto para a rua, especialmente em direção aos espaços à beira-mar, em um movimento de idas e vindas, atento aos elementos materiais e aos seus semelhantes, aos quais observa para desenvolver tanto uma experiência pessoal quanto se identificar com as experiências da alteridade a fim de estabelecer um íntimo contato com a exterioridade. Em uma das prosas, aparece dentro de um barquinho, envolvido pela imensidão do mar e pelo brilho das estrelas; porém, a escuridão da noite o impede de visualizar a paisagem que se expande até a linha do horizonte. Esta obscuridade desperta no poeta sentimentos contraditórios, o desejo de uma experiência metafísica com a divindade e a angústia diante da consciência da impossibilidade em satisfazer tal anseio, uma vez que dos deuses resta apenas um vazio. Um conforto, no entanto, advém ao acender um cigarro, cuja luz ilumina o espaço à semelhança de uma estrela, dando-lhe a sensação de existir, de "habitar" o mundo, ou seja, de fazer parte, ser uma pequena parcela da vida que se desenvolve e se movimenta incessantemente no espaço ao seu redor, na alteridade exterior: «J'aime allumer une 
cigarette au milieu de la mer. C'est un minuscule point rouge sur le bleu. Un point d'incandescence, de grésillement et de chaleur. Il signifie que j'existe: je suis une graine, une pépite d'homme, une parcelle d'âme en larmes [...]» (MAULPOIX, 2005b, p. 103). Por outro lado, o poeta lança seu olhar atentamente para as atitudes, as falas, os gestos cotidianos, enfim, para a movimentação dos outros seres humanos, eles também às voltas com sua contingência:

Ils se déplacent. Ils songent à se placer. [...] Promptement, ils s'habillent, se dévêtent, et se rhabillent encore devant le miroirs. Cela, semble-t-il, les occupent. [...] Vivants, ils vont les mains devant. [...] Ils racontent tout haut leurs soucis, expliquent leurs misère, découpent des images, inventent des histoires, chantent à tue-tête et se trémoussent sur des musiques. Ils fouillent parfois dans leur mémoire pour y chercher un mots qui se puisse murmurer à l'oreille d'une femme [...] (MAULPOIX, 2005b, p. 44-5).

Ao observar as vivências da alteridade, a voz poética acaba por se projetar em suas experiências de maneira que o outro se torna um prolongamento ou uma parte de si mesma. Para exteriorizar seus sentimentos, suas emoções e suas queixas, a voz lírica busca uma orelha, chamando para o discurso a presença de um "tu" que pode ser Deus, o ser amado, um animal, um objeto inanimado ou até uma pessoa qualquer. Entretanto, esta alteridade que corresponde ao "tu" pode expressar também uma parte da própria voz lírica - o que remete a uma fragmentação da subjetividade -, e ainda, a um "tu" que se exterioriza por meio da primeira pessoa do singular e que, assim, assume a autorreflexidade lírica. O lirismo crítico constitui o que Maulpoix denomina a quarta pessoa do singular, uma pessoa potencial e contraditória que trabalha em conjunto todas as instâncias discursivas, mas que não corresponde "ni le 'je' biographique de l'individu, ni le 'tu' dramatique du dialogue, ni le 'il' épique ou romanesque" (MAULPOIX, 1998, p.36). Todavia, o sujeito lírico, na verdade, não existe, conforme Maulpoix (1998, p.32), 
porque ocupa o intervalo invisível e móvel entre o "je" o "moi", isto é, estabelece-se no intervalo e no deslocamento entre o indivíduo e o conteúdo de sua vida afetiva, entre o que a criação deseja e seu conteúdo. Desta forma, a instância poética de Une histoire de bleu se fragmenta nas várias pessoas do discurso, il (s), je, on, nous, tu e vous, a fim de proporcionar uma abertura da interioridade para as diversificadas transições da alteridade na realidade contingente, vivenciando suas percepções, sensações, tristezas, dificuldades, etc. como se fossem experimentadas por si mesma.

$\mathrm{O}$ autor contemporâneo caracteriza o poeta como um ser que caminha sobre a terra, à semelhança do "flâneur" baudelairiano, em uma errância em que importa mais o movimento de seguir sempre adiante apenas guiado pelo movimento ou pela visualização de algum detalhe na paisagem, uma pessoa, um objeto ou um lugar particular, que lhe desperta uma percepção mais aprofundada da realidade, como no itinerário do poeta em Ne cherchez plus mon coeur (1986):

Il lui arrive de marcher des heures à travers la ville, improvisant l'itinéraire au gré de la perspective, du tumulte, des coloris, ou pour la seule inclination des passants qui déambulent par là plus vifs et plus légers. Cette marche le délivre. Ce n'est plus lui qui va ni qui décide, mais l'oeil et le pas des silhouettes qu'il accompagne. Pour une mèche de cheveux, il change de trottoir. Quelques boutiques le retiennent: l'une vend des couteaux au pied de la montagne Saint-Geneviève, une autre des vieux livres symbolistes parmi des foulards et des Tour Eiffel au bord de la Seine. À l'angle d'une rue, son histoire termine, le ciel s'entrouve, c'est presque la mer. C'est un marché parfois, avec des poissons et des fruits, des cris et des parfums mêlés comme en province. Parfois, c'est une école à l'heure de la récréation: on s'arrête, on observe, on écoute, on s'accroche, on regarde toujours à travers des grilles (MAULPOIX, 2012, p.12).

Nos textos de Maulpoix, o poeta se identifica e se projeta no 
homem comum - com o qual comunga o caráter efêmero da vida e o contexto sócio-cultural -, que todos os dias espera pelo transporte que o conduz para suas ocupações, começando e recomeçando suas experiências que são sempre as mesmas sendo também outras: “[...] celui qui attend l'autobus ou le train de banlieue, les ailes repliées sous l'imperméable, à la même heure toujours sur le même quai, prêt à s'embarquer vers le premier jour de sa propre vie." (MAULPOIX, 2005b, p.51). Este homem, que seria um alterego do próprio poeta, como o albatroz do soneto baudelairiano, apresenta-se em uma postura de recolhimento com os braços/ asas dobrados próximos ao corpo, melancólico devido ao apecto repetitivo de seu cotidiano. No entanto, caracteriza ainda o ser humano mergulhado na contingência como alguém sem traços definidos, sem uma identidade definida, como se todos os homens se assemelhassem e comungassem a mesma aparência física, os gestos, os sentimentos, as experiências, etc., sendo somente "fantoches de açúcar" que perdem a singularidade de sua identidade ao se submeterem e se deixarem manipular pelos mecanismos da sociedade contemporânea: "De ses semblables, il mélange les traits, pour qu'on ne puisse les reconaître et qu'ils se sentent ainsi moins seuls, moins prisonniers de leur figure et de leur corps périssable [...]. il ne donne pas de nom à ces patins de sucre [...]" (MAULPOIX, 2005b, p.51). Na medida em que se projeta nas vivências dos outros também compartilha essa despersonalização do ser humano nas grandes cidades, despersonalização que se inicia na obra baudelairiana onde, conforme a leitura de Maulpoix (2000, p. 94), as diversas personagens criadas pelo poeta em Spleen de Paris, os pobres, a pequena velha, o louco, o cachorro, Madame Bistori, o vidraceiro, etc. são manequins que vestem e encarnam os vícios e as dores causadas por sua imersão no real, ou seja, na Paris da segunda metade do século XIX, que se define por seus lugares malditos que, entretanto, exercem um intenso fascínio sobre o poeta. Como lembra Maulpoix ao recuperar o poema "Les petites vieilles" de Les fleurs du mal e as errâncias do poeta em Spleen de 
Paris, "dans les rues de la ville: c'est bien là, en effet, qu'il rôde, qu'il va, qu'il court, qu'il cherche, celui que Baudelaire appelle 'le peintre de la vie moderne', lancé dans le 'grand désert des hommes' à la poursuite de 'ce quelque chose qu'on nous permettra d'appeler la modernité'” (MAULPOIX, 2002, p. 73). No entanto, a cidade por onde o "flâneur" transitava no passado, não permite mais que o poeta se lance na aventura de extrair o eterno do transitório, pois ao se transformar em uma metrópole no contexto contemporâneo, absorve os seres humanos e a si mesma, criando uma ruptura cada vez mais acentuada entre a subjetividade e a alteridade:

Or, ce schéma baudelairien a perdu de sa force, en même temps que s'épuisait la modernité et que la ville elle-même se trouvait absorbée et défaite en mégapole, réseau, banlieues: la combinatoire et l'interconnexion y prenant le pas sur la dialectique, la saturation des signaux et la bousculade accélérée des corps y occultant la lisibilité des signes et des figures. Dans l'horizon contemporain, le bavardage du village global recouvre les bruits et les voix de la ville. Indéfiniment distendue, elle ne donne plus l'échelle ni le plan de l'humaine condition. [...] Dans les rues de la ville, il y a les excréments canins. La passante d'aujourd'hui téléphone en marchant. Elle porte sur les oreilles un walkman. La passante de naguère est devenue touriste. La rue appartient aux 'rollerbladers': à ceux qui circulent et qui glissent, et non à ceux qui cherche ce mystérieux quelque chose qu'on appelle 'la modernité'. Ceux qui roulent sur leurs patins ou sur leur trotinette ne cherchent rien: ils jouissent d'eux-mêmes. Voici que la rue s'est changée en salle de jeux ou terrain de sport (MAULPOIX, 2002, p.77-9).

Neste contexto, Maulpoix se indaga, inspirado em Baudelaire, «que cherche-t-il [le poète]?», encontrando a resposta ao analisar a deambulação do poeta no texto lírico-crítico Les ruines de Paris (1977), de Jacques Redá:

À l'oeil du baguenaudeur postmoderne n'apparaissent plus 
de créatures ni de lieux exemplaires, investis d'une valeur morale, susceptibles de se coordonner pour former des figures lisibles et emblématiques. [...] Les grandes identités symboliques qui pour Baudelaire s'appelaient le pauvre, la prostituée, l'enfant, la vieille, ne sont plus sous la plume d'aujourd'hui que des silhouettes incertaines de gens qui font la queue devant une boulangerie [...]. La grande ville est creuse et vacante. Tout a déjà eu lieu: le monde est pleine de lieux communs (MAULPOIX, 2009, 191-2).

Inserido no espaço terreno contingente, seu único horizonte possível, o homem contemporâneo passa a ser um viajante sempre na espera de um acontecimento que venha quebrar a rotina cotidiana e que represente a aventura de uma outra ou uma nova partida, isto é, de uma experiência renovada. Com efeito, em Une histoire de bleu, o poeta acaba por se transformar em um viajante que descreve um deslocamento constante de idas e vindas, de sua casa para o mundo exterior, sempre no aguardo ou na esperança de vislumbrar a manifestação de um instante poético: "De quais de gares et d'aéroports, de valises faites et défaites, de piles de chemises ou de livres, et d'encre noire qui vire au bleu" (MAULPOIX, 2005b, p. 108). Assim, seu trajeto lírico corresponde a um ir e vir, das partidas para o mundo ao ansioso retorno para o aconchego de sua casa junto à amada e à intimidade de seu quarto - "Mais toujours je reviens vers elle, vers sa maison odorante et propre où il y a beaucoup de place pour mes après-midi de pages blanches" (MAULPOIX, 2005b, p. 109) -, em detrimento da multiplicidade de trajetórias do lirismo apontadas por Maulpoix (2005a, p.178-9) na obra baudelairiana: vertical, horizontal, em linhas quebradas, oblíquas, etc.. Em Une histoire de bleu, o quarto da casa do poeta denota, então, o lugar de recolhimento em que se volta para sua interioridade e para a escrita poética, em oposição aos impessoais quartos de hotel cujos corredores dão sempre para outros quartos com as portas fechadas, onde somente lhe resta abdicar ao prazer da escrita: “je ne m'y installe guère. Couloirs plutôt, ils donnent sur des chambres. Je cogne aux portes et vais de défaits en abdications. Les 
jours de mes chimères sont comptés» (MAULPOIX, 2005b, p. 108). 0 poeta contemporâneo é o poeta das estações de trem ou de metrô e dos aeroportos, que só pode temporariamente experimentar a sensação de atingir o céu ao viajar de avião, retornando sempre para seu ponto de partida terreno, onde mesmo as viagens de trem não lhe permitem lançar-se além do horizonte. Desta forma, as viagens não permitem ao poeta lírico-crítico uma evasão em que possa ultrapassar seu horizonte rumo ao infinito, pois correspondem apenas a um trânsito pelo espaço terreno contingente que ressalta ainda mais sua condição finita.

Como também assinala Maulpoix (2000, p.89), ao refletir acerca do transitório a partir do pensamento baudelairiano, cabe ao homem ser um lugar de passagem tanto quanto um passageiro. Enquanto passageiro, o poeta se deixa levar pelo movimento da vida cotidiana tendo como espelho a alteridade, porém, pode viajar imóvel diante da página em branco, seja para um passado perdido na infância, seja por meio da tentativa de satisfazer seu desejo pelo infinito. Contudo, como um "lugar de passagem" se coloca a disposição do efêmero na procura de uma apreensão mais primária, imediata e profunda da realidade pela percepção sensorial, registrada pela escrita. De fato, seu corpo permanece sempre alerta, estimulado pelos sentidos que captam, por exemplo, o lento movimento dos barcos amarrados no porto ao anoitecer, o céu que readquire uma tonalidade azulada após a tempestade que cai sobre a cidade, a alegria sensual de homens e mulheres que se encontram no fim da tarde nos bares para o happy-our, o soar do sino da igreja badalando oito horas, o prazer em acender um cigarro dentro de um barquinho em alto-mar ou em ouvir o som das ondas que se quebram na praia atrás das venezianas de um quarto, ou ainda, relembrar a voz da mãe soletrando o alfabeto na infância quando ouve o barulho do mar. São instantes frágeis e efêmeros registrados pela escrita, que originada a partir de um estado poético despertado pela percepção, capta apenas parcelas da realidade e as transforma em fugazes instantes de poesia, como ao descrever a 
beleza que se depreende da observação de um jardim em uma tarde de domingo: "Des jardins superflus poussent plus haut vers le large, odorants de menthes, de myosotis et d'impatientes. Une rumeur de lilas dégringole vers la mer quand, sur les balcons de bois peints, le coeur des marins s'éclabousse» (MAULPOIX, 2005b, p.34).

0 poeta procura fazer com que o ato de escrita ocorra o mais próximo possível do momento de sua percepção, de modo que por seu corpo ressoe os frágeis acontecimentos da realidade exterior, convertendo-os em escrita poética. Notamos este processo, por exemplo, em uma das pequenas prosas de Une histoire de bleu, pois enquanto a chuva cai, o poeta vai acompanhando lentamente as sensações e emoções que lhe são despertadas pela sonoridade da água, que produz uma linguagem que corresponde ao estado poético, ou seja, ao lirismo:

Tard en automne, lorsque la pluie tombe à petit bruit, il me plaît de croire entendre le ciel pleurer. Écrire ajoute alors ses larmes compliquées à la transparente coulée qui fait tinter le toit d'ardoise et le zinc du chéneau. [...] À cette heure et en cette saison, l'on ne brusque pas le langage, on s'y abandonne, sûr que pour une fois la justesse est en un tel acquiescement au murmure de la pluie et à l'obscurité de la fenêtre (MAULPOIX, 2000b, p. 110).

Como forma de apreender esta temporalidade efêmera, em que os limites entre o passado, o presente e o futuro são muito tênues, o poeta carrega consigo um caderninho de notas, nomeado no texto "Carnet d'un éphémère" em Une histoire de bleu, onde vai anotando ou rabiscando estes momentos fugazes recolhidos do contato com a alteridade, tanto a alteridade humana quanto a alteridade urbana ou natural, ou as reflexões e os questionamentos relativos à escrita poética. 0 caderninho de notas fornece ao poeta um instrumento que lhe permite registrar os momentos efêmeros que são despertados por suas atentas observações da realidade contingente, porque possui a vantagem de acompanhá-lo em suas idas e vindas, em seus deslocamentos da rua para a solidão do quarto, das viagens 
para o aconchego do lar e vice-versa; portanto, o caderninho de notas atua como uma extensão do poeta e por isto participa de sua transitoriedade entre o interior e o exterior, a reflexão crítica e a revelação poética. Tende ainda a dar conta do anseio de Maulpoix de transformar as experiências da vida, sejam os momentos especiais em que consegue vislumbrar o efêmero, seja em suas caminhadas em busca de uma aproximação com seus semelhantes ou até com a divindade, em uma escrita poética durante seu transitar pela realidade contingente, por isto, o poeta afirma:

À vrai dire, je n'écrit pas, je note, furieusement. Un carnet à petits carreaux, sur une borne, au carrefour, près du panneau de l'abribus. Là où s'affiche la fille en soutiengorge noir, au regard de madone. Là où le Christ de pierre grise penchait naguère la tête vers les vieillards. Genoux pliés, je griffonne en faute. Marchant dans la lumière des feux et des enseignes, je me sauve, je me révérbère [...]. Parmi tous ceux qui passent et dont le coeur cogne tout prés. (MAULPOIX, 2005b, p. 106).

É interessante salientar que o registro rápido das percepções, das sensações, das descobertas, das reflexões e dos questionamentos acaba por ser o ponto de partida para a escrita de outras obras lírico-críticas de Maulpoix que se relacionam inclusive com sua experiência pessoal, como sua viagem para a China que dá origem a obra em forma de um pseudo-diário Chute de pluies fines (2002), sendo que algumas páginas do caderno de anotações manuscrito resultante desta viagem podem ser vistas no website do escritor, ou ainda, L'Amérique n'existe pas (2014), que corresponde a um caderno de viagem relativo a sua estadia em Los Angeles, nos Estados Unidos.

No entanto, a fugacidade das experiências desenvolvidas com a alteridade mostra para o poeta a fragilidade da vida humana, que caminha passo a passo para a finitude desde o nascimento até a morte, bem como para a irremediável destruição do ser humano e também de suas construções. Como consequência o poeta registra "as diversas formas de morrer" em Une histoire de bleu, onde 
diferentes imagens da morte e de mortos invadem as pequenas prosas: cadáveres de afogados no fundo do mar, uma adolescente em seu leito funerário com um buquê de lilazes entre os seios, velhas caquéticas e carros funerários, os cabelos brancos e as rugas que vão deixando rastros no rosto, a cidade solitária em ruínas, os amores desfeitos, etc. Estas imagens, entretanto, são apresentadas com um tom ao mesmo tempo melancólico e doce, pois o autor não deseja extrair a beleza da morte a fim de atingir um sublime - como o faz Baudelaire, por exemplo, no poema «Une Charogne», mas mostrar a efêmeridade da própria morte:

Une coeur de verre plié. Un tas de bois devant la porte. Un bouquet de lilas entre les seins de la petite morte. Un trait de plume au bas de la page dont continue de s'écouler, longtemps après, l'encre invisible. Une chambre sans meuble, où s'allonguer un soir à même le sol dans un merveilleux corps sans apparence ni nudité (MAULPOIX, 2005b, p. 121).

Por isto, o poeta adverte que «bientôt ne subsistera de la vie passée que bouffissure. De l'amour berloques, les tirelires brisées et les papiers froissés. Il ne restera du coquelicot et du bleuet que la tumeur. Rien qu'une histoire décomposée, dans ses grands haillons blancs et noirs» (MAULPOIX, 2005b, p. 117). Histórias que não podem ser plenamente recompostas porque delas permanecem somente alguns restos, algumas parcelas e alguns fragmentos como a escrita do poeta que tem consciência de sua efemeridade, mas que encontra no seio da finitude o sentido da vida e da escrita: «La mort est en nous l'idée la plus belle, l'idée mère, l'idée douce et sans bornes, la seule idée point trop folle pour laquelle on puisse avoir encore le goût de vivre» (MAULPOIX, 2005b, p. 121). Como o presente sempre se converte instantaneamente em passado, a escrita do poeta se mantém sempre no frágil intervalo entre o que já passou e o que ainda não é, estando, portanto, às voltas com a tentativa de evocar a perda, construir sua escrita com o que resta 
como forma reatar na página em branco os laços que a realidade desfaz.

Enfim, por meio de um intenso processo de releitura da obra baudelairiana, Jean-Michel Maulpoix constrói em Une histoire de bleu a escrita de um efêmero, escrita lírico-crítica que lhe permite articular a subjetividade, a realidade e a linguagem, traçando um rumo para a poesia francesa contemporânea que se diferencia da experimentação desenvolvida pela pós-poesia, que se opõe ao lirismo em seu esforço por romper com a tradição e os modelos perpetuados pela tradição da poesia.

\begin{abstract}
Agradecimento
Agradeço à Fundação de Amparo à Pesquisa do Estado de São Paulo (FAPESP) pelo financiamento da pesquisa, da qual este artigo faz parte.
\end{abstract}

\title{
REFERÊNCIAS BIBLIOGRÁFICAS
}

BAUDELAIRE, C. Les fleurs du mal. Paris: Gallimard, 1991.

. O Pintor da vida moderna. Belo Horizonte: Autêntica Editora, 2010.

COLLOT, M. COLLOT, M. Dossier - Lyrisme et Littéralité, 2009. Disponível em <http://periodicalrs.narr.de/index. php/lendemains/.../157>. Acesso em 05/06/2012.

La matière-émotion. Paris: PUF, 1997.

. L'horizon fabuleux. v.I. Paris: José Corti, 1988.

FRYE, N. Anathomie de la critique. Paris: Gallimard, 1977. 
GAME, J. Actualité du moderne. Magazine Littéraire. Paris, n. 396, mars, 2001.

JACCOTTET, P. L'Improbable. Paris: Mercure de France, 1992.

MAULPOIX, J. M. Adieux au poème. Paris: José Corti, 2005a.

. Chutes de pluie fine. Paris: Mercure de France, 2002.

. Du Lyrisme. Paris: José Corti, 2000.

. Entretien avec Jean-Michel Maulpoix par Laurence Liban. L'Express. Paris, 2006.

. Introduction à une poétique du texte offert Apostilles. 2001. Disponível em <http://www.maulpoix. net>. Acesso em 12/07/2010.

. La poésie comme l'amour. Essai sur la relation lyrique. Paris: Mercure de France, 1998.

. L'Amérique n'existe pas. Paris: Le Nouveau Recueil, 2014.

. Le poète perplexe. Paris: José Corti, 2002.

. Ne cherchez plus mon coeur. Paris: Publiepapier, 2012.

. Une histoire de bleu suivi de L'instinct de ciel. Paris:

Gallimard, 2005b.

. Pour un lyrisme critique. Paris: José Corti, 2009. 
PINSON, J.C. Habiter en poète. Seyssel: Champ Vallon, 1995.

RÉDA, J. Les ruines de Paris. Paris: Gallimard, 1993. 
